\title{
Perifissural nodules: ready for application into lung cancer CT screening?
}

\author{
Anton Schreuder ${ }^{1}$, Cornelia M. Schaefer-Prokop ${ }^{1,2}$ \\ ${ }^{1}$ Department of Radiology, Nuclear Medicine, and Anatomy, Radboudumc, Nijmegen, The Netherlands; ${ }^{2}$ Department of Radiology, Meander \\ Medisch Centrum, Amersfoort, The Netherlands \\ Correspondence to: Anton Schreuder. Department of Radiology, Nuclear Medicine, and Anatomy, Radboudumc, Geert Grooteplein 10, 6525 GA \\ Nijmegen, The Netherlands. Email: antoniusschreuder@gmail.com. \\ Comment on: Han D, Heuvelmans MA, van der Aalst CM, et al. New Fissure-Attached Nodules in Lung Cancer Screening: A Brief Report From The \\ NELSON Study. J Thorac Oncol 2020;15:125-9.
}

Submitted Apr 17, 2020. Accepted for publication Apr 21, 2020.

doi: $10.21037 /$ atm-20-3384

View this article at: http://dx.doi.org/10.21037/atm-20-3384

The National Lung Screening Trial (NLST) was the first multicentered randomized controlled trial which showed that chest CT scans for early lung cancer detection in a high-risk population significantly reduced lung cancer mortality by $20 \%$ compared to a control group (1). Though these results were groundbreaking, $24 \%$ of all screening results were false positives; their definition for a positive outcome was the presence of a solid nodule $\geq 4 \mathrm{~mm}$ in diameter. Nine years after the NLST results were published, the Dutch-Belgian Lung Cancer Screening Trial (NELSON) reported a lung cancer mortality reduction of $24 \%$ and a false-positive rate to $2 \%$ (2). This false-positive reduction was achieved by volumetrically reassessing indeterminate nodules for growth instead of immediate referral to the pulmonologist. With nodule growth being the best visual predictor of malignancy, this implies that new nodules (not visible in prior scans) have a higher lung cancer probability than those found in the baseline scan (3). Han et al. (4) investigated the incidence of perifissural nodules (PFN) exclusively among new nodules detected in follow-up scans from the NELSON study.

PFNs are a radiological classification of non-calcified solid pulmonary nodules, most of which are assumed to be benign intrapulmonary lymph nodes (5-8). Typical CT features include well-defined and regular borders, a polygonal, triangular, or ovoid shape, proximity to a pulmonary visceral pleura, and location in the lower lobes or below the level of the carina (9-19). Most studies determined that nodules classified as PFNs by radiologists or trained readers did not turn out to be cancerous, even when the PFN exhibited size changes in a subsequent scan (6). The added value of categorizing nodules as PFNs is hereby to reduce the unnecessary follow-up of nodules guaranteed to be benign. However, two studies have reported that there is an unlikely but not impossible chance that some lung cancer nodules may be classified as PFNs $(7,20)$. Being a relatively new and underinvestigated topic, more research is required to recommend a new nodule category which can be used to downgrade risk management. Han et al. (4) observed that none of the new nodules which were classified as PFNs were malignancies within the follow-up time. This finding that PFNs can reliably be considered benign among nodules with a higher a priori malignancy probability is a welcome addition to the literature.

Han et al. (4) included all 1,484 new solid nodules $\geq 15 \mathrm{~mm}^{3}$ detected in NELSON's follow-up CTs $\left(2^{\text {nd }}, 3^{\text {rd }}\right.$, and $4^{\text {th }}$ screening rounds at 1,3 , and 5.5 years after the baseline scan, respectively) (4). Seven percent $(107 / 1,484)$ were recorded as fissure-attached nodules by NELSON radiologists. Blinded to the outcomes, two radiologists independently reassessed the nodules for fissural attachment and classified them as typical PFNs, atypical PFNs, or nonPFNs according to the definitions by de Hoop et al. (6); a third radiologist arbitrated disagreements. Ninetyseven new fissure-attached nodules were included in the analysis, of which $43 \%(42 / 97)$ and $17 \%$ (16/97) were classified as typical and atypical PFNs, respectively. All 10 
malignancies in this study cohort (10\%) were among the remaining nodules classified as non-PFNs $(40 \%, 39 / 97)$. Other unsurprising but important findings are that nodules classified as PFNs are typically smaller than non-PFN malignancies and that none of the malignancies had a lentiform or triangular shape.

The authors mentioned two limitations: one was that some CT scans were not retrievable. The other was that the sample size was small $(n=97)$; the justification was that the full data set of new nodules from the second-largest randomized controlled lung cancer screening study was used. Furthermore, the CTs were all of $1 \mathrm{~mm}$ slice thickness while most from the NLST are at least $2 \mathrm{~mm}$ thick. It is therefore likely that the largest collection of thin-slice chest CT scans from an individual lung cancer screening trial is from the NELSON. Higher quality scans are especially important for being able to assess nodules $<10 \mathrm{~mm}$. However, the sample size would have been considerably larger had the nodule selection criteria been less strict regarding fissure attachment.

It was mentioned that the prevalence of PFNs among new solid nodules $(4 \%, 58 / 1,484)$ was much lower than that reported in other studies ( $20 \%$ to $28 \%)(5,6,8)$, but no reasons were discussed. The most likely explanation is that the proportion of benign nodules among new nodules is lower than at baseline. A second contributing factor is that-unlike other PFN studies-fissure attachment was an inclusion criterion. The decision to exclusively reassess fissure-attached nodules is only partially justifiable: an ongoing issue of classifying nodules as PFNs is the lack of a clear definition as to what a PFN is. Four different definitions have been used to date (5-8). However, one of the common criteria among all definitions is that nodules which are not fissure-attached but still within at least $5 \mathrm{~mm}$ from a major, minor, or accessory fissure are still eligible for classification as PFNs. Han et al. (4) applied the definition from de Hoop et al. (6) which states that typical PFNs must be fissure-attached but atypical PFNs have no restrictions regarding fissure distance. This means that the reported (atypical) PFN prevalence rate is an underestimation.

A replacement nodule selection criterion which may have been considered is a size limit: the malignant fissureattached nodules (a), (b), (e), (h), (i), and (j) in Figure 2 appear to have diameters $\geq 15 \mathrm{~mm}$ (not reported) which would often justify a PET/CT or biopsy. Also considering that intrapulmonary lymph nodes $\geq 12 \mathrm{~mm}$ are rare (9-19), only nodules classified as PFNs within an indeterminate size range should have their risk management downgraded (e.g., approximately 6 to $10 \mathrm{~mm}$ (21-23); lower for new nodules). Assuming that the vast majority of benign nodules in the study were $<10 \mathrm{~mm}$, the probability that a lung cancer is misclassified as a PFN was low to begin with. The proportion of malignant nodules included in Ahn et al. (5) and de Hoop et al. (6) were also small [ $\leq 2 \%$, exact frequency not provided by de Hoop et al. (6)]; Schreuder et al. (7) and Mets et al. (8) used a malignancy-enriched sample to compensate.

Acknowledging that brief reports only have a 1,500 word limit, it is understandable that Han et al. (4) did not report the kappa of agreement between readers in the reassessment of fissure-attached nodules. Schreuder et al. (7) demonstrated (using a different PFN definition) that there is only a fair to moderate agreement among experienced radiologists when classifying nodules as PFNs, leading to some variation in the misclassification rate of cancer nodules. It would therefore be informative to know the number of nodules which required arbitrage and whether any of those were malignancies.

It also remains unclear whether nodules were assessed in other directions besides the axial plane because each nodule was only labelled with a two-dimensional shape (i.e., lentiform, triangular, or other). This is the common practice in all other imaging studies on intrapulmonary lymph nodes and PFNs (5,6,8-19,24). Especially with the improvements in scan quality, future PFN studies should report nodule shapes in all three orthogonal planes. This would reduce the chance of overlooking suspicious morphology in the sagittal or coronal planes. Though the misclassification of cancers as PFNs is not completely avoidable, this new practice would work towards keeping this to a minimum.

With the effectiveness of CT screening in reducing lung cancer mortality having been demonstrated in two large randomized controlled trials $(1,2)$, strategies to improve efficiency need to be investigated. One facet is to reduce the unnecessary workup of benign nodules (false positives) without delaying the diagnosis of malignancies (false negatives). Omitting nodules classified as PFNs from additional diagnostic tests appears to be a highly reliable and effective strategy for contributing towards this goal. This approach had indicated trustworthiness in screening $(5,6)$ and clinical settings $(8)$ and in pediatric cohorts $(25,26)$; even PFNs which grew or shrunk in a follow-up scan were not found to be cancerous (6). Han et al. (4) expand the range of evidence to include new nodules. Future research needs to work towards a standardized definition of PFNs and its validation in a sufficiently cancer-rich and high- 
quality CT cohort.

\section{Acknowledgments}

Funding: None.

\section{Footnote}

Provenance and Peer Review: This article was commissioned by the editorial office, Annals of Translational Medicine. The article did not undergo external peer review.

Conflicts of Interest: Both authors have completed the ICMJE uniform disclosure form (available at http://dx.doi. org/10.21037/atm-20-3384). The authors have no conflicts of interest to declare.

Ethical Statement: The authors are accountable for all aspects of the work in ensuring that questions related to the accuracy or integrity of any part of the work are appropriately investigated and resolved.

Open Access Statement: This is an Open Access article distributed in accordance with the Creative Commons Attribution-NonCommercial-NoDerivs 4.0 International License (CC BY-NC-ND 4.0), which permits the noncommercial replication and distribution of the article with the strict proviso that no changes or edits are made and the original work is properly cited (including links to both the formal publication through the relevant DOI and the license). See: https://creativecommons.org/licenses/by-nc-nd/4.0/.

\section{References}

1. National Lung Screening Trial Research Team; Aberle DR, Adams AM, et al. Reduced lung-cancer mortality with low-dose computed tomographic screening. N Engl J Med 2011;365:395-409.

2. de Koning HJ, van der Aalst CM, de Jong PA, et al. Reduced Lung-Cancer Mortality with Volume CT Screening in a Randomized Trial. N Engl J Med 2020;382:503-13.

3. Walter JE, Heuvelmans MA, de Jong PA, et al. Occurrence and lung cancer probability of new solid nodules at incidence screening with low-dose CT: analysis of data from the randomised, controlled NELSON trial. Lancet Oncol 2016;17:907-16.

4. Han D, Heuvelmans MA, van der Aalst CM, et al. New
Fissure-Attached Nodules in Lung Cancer Screening: A Brief Report From The NELSON Study. J Thorac Oncol 2020;15:125-9.

5. Ahn MI, Gleeson TG, Chan IH, et al. Perifissural Nodules Seen at CT Screening for Lung Cancer. Radiology 2010;254:949-56.

6. de Hoop B, van Ginneken B, Gietema H, et al. Pulmonary perifissural nodules on CT scans: rapid growth is not a predictor of malignancy. Radiology 2012;265:611-6.

7. Schreuder A, Van Ginneken B, Scholten ET, et al. Classification of CT pulmonary opacities as perifissural nodules: Reader variability. Radiology 2018;288:867-75.

8. Mets OM, Chung K, Scholten ET, et al. Incidental perifissural nodules on routine chest computed tomography: lung cancer or not? Eur Radiol 2018;28:1095-101.

9. Hyodo T, Kanazawa S, Dendo S, et al. Intrapulmonary lymph nodes: Thin-section CT findings, pathological findings, and CT differential diagnosis from pulmonary metastatic nodules. Acta Med Okayama 2004;58:235-40.

10. Kradin RL, Spirn PW, Mark EJ. Intrapulmonary lymph nodes. Clinical, radiologic, and pathologic features. Chest 1985;87:662-7.

11. Bankoff MS, McEniff NJ, Bhadelia RA, et al. Prevalence of pathologically proven intrapulmonary lymph nodes and their appearance on CT. AJR Am J Roentgenol 1996;167:629-30.

12. Miyake H, Yamada Y, Kawagoe T, et al. Intrapulmonary lymph nodes: CT and pathological features. Clin Radiol 1999;54:640-3.

13. Matsuki M, Noma S, Kuroda Y, et al. Thin-section CT features of intrapulmonary lymph nodes. J Comput Assist Tomogr 2001;25:753-6.

14. Sykes AMG, Swensen SJ, Tazelaar HD, et al. Computed tomography of benign intrapulmonary lymph nodes: Retrospective comparison with sarcoma metastases. Mayo Clin Proc 2002;77:329-33.

15. Kawaguchi T, Sawabata N, Nakai T, et al. Clinical and pathological characteristics of surgically resected intrapulmonary lymph nodes: Can they be differentiated from other malignant nodules? Respir Investig 2018;56:473-9.

16. Oshiro Y, Kusumoto M, Moriyama N, et al. Intrapulmonary lymph nodes: thin-section CT features of 19 nodules. J Comput Assist Tomogr 2002;26:553-7.

17. Ishikawa H, Koizumi N, Morita T, et al. Ultrasmall intrapulmonary lymph node: Usual high-resolution computed tomographic findings with histopathologic 
correlation. J Comput Assist Tomogr 2007;31:409-13.

18. Wang CW, Teng YH, Huang CC, et al. Intrapulmonary lymph nodes: computed tomography findings with histopathologic correlations. Clin Imaging 2013;37:487-92.

19. Barnett J, Pulzato I, Wilson R, et al. Perinodular Vascularity Distinguishes Benign Intrapulmonary Lymph Nodes from Lung Cancer on Computed Tomography. J Thorac Imaging 2019;34:326-8.

20. Winkler Wille MM, van Riel SJ, Saghir Z, et al. Predictive Accuracy of the PanCan Lung Cancer Risk Prediction Model -External Validation based on CT from the Danish Lung Cancer Screening Trial. Eur Radiol 2015;25:3093-9.

21. Goo JM. Juxtapleural (Perifissural) Nodules: Does Location Mean a Benign Lesion? Radiology 2018;288:876-7.

22. Callister MEJ, Baldwin DR, Akram AR, et al. British Thoracic Society guidelines for the investigation and management of pulmonary nodules: accredited by NICE.

Cite this article as: Schreuder A, Schaefer-Prokop CM. Perifissural nodules: ready for application into lung cancer CT screening? Ann Transl Med 2020;8(19):1254. doi: 10.21037/ atm-20-3384
Thorax 2015;70:ii1-54.

23. The American College of Radiology. Lung CT Screening Reporting \& Data System v1.1 [Internet]. 2019. Available online: https://www.acr.org/Clinical-Resources/ Reporting-and-Data-Systems/Lung-Rads

24. Schreuder A, Schaefer-Prokop CM, Scholten ET, et al. Lung cancer risk to personalise annual and biennial followup computed tomography screening. Thorax 2018. doi: 10.1136/thoraxjnl-2017-211107.

25. Verhagen M V, Smets AMJB, van Schuppen J, et al. The impact of reconstruction techniques on observer performance for the detection and characterization of small pulmonary nodules in chest CT of children under 13 years. Eur J Radiol 2018;100:142-6.

26. Samim A, Littooij AS, van den Heuvel-Eibrink MM, et al. Frequency and characteristics of pulmonary nodules in children at computed tomography. Pediatr Radiol 2017;47:1751-8. 